\title{
TOTAL HIP REPLACEMENT IN CHILDREN WITH JUVENILE CHRONIC ARTHRITIS
}

\author{
C. RUDDLESDIN. B. M. ANSELl, G. P. ARDEN, M. SWANN \\ From the Canadian Red Cross Memorial Hospital, Taplow
}

\begin{abstract}
The results of 75 total hip replacements in 42 children with juvenile chronic arthritis are reported after a mean follow-up of 5.4 years. Their ages ranged from 11 to nearly 17 years at operation and many had active disease. Severe pain and marked stiffness of the hips were limiting their independence. At least half of the children were still growing and continued to grow after operation. The patients were carefully selected and gratifying results were obtained, but pre-operative assessment and overall supervision by a rheumatologist are important.

Technical difficulties related to the size and maldevelopment of the hip are discussed. There was no infection and the single case of loosening of a femoral component after nine years has been successfully revised.
\end{abstract}

In $9 \%$ of patients with juvenile chronic arthritis the hip is involved within one year of onset of the disease (Ansell 1978). Development of the hips is impaired both by loss of the stresses of normal weight-bearing and later by the destructive arthritis itself (Fig. 1). Whilst the disease affects many joints, the involvement of the hips is the single most important cause of loss of mobility in these children. Consequent social and educational isolation, with increasing dependence on relatives, hospitals and residential institutions, affects the child at a most important stage of adolescent development.

There is, however, some concern about the fate of prosthetic implants in the young patient. Problems of component wear and fatigue, aseptic loosening, implant rejection and other long-term effects of cement or metal implants on the surrounding tissues are recognised (Bagó et al. 1984). The additional problem presented by possible continued growth after the insertion of the implant is a factor in deterring orthopaedic surgeons from operating on these young patients. However, the overall growth of those affected by the disease is less than normal, whilst in some patients corticosteroids used to control the disease may have caused further growth retardation and early epiphysial fusion. Half of our patients continued to grow after operation, but less than unaffected children. These patients are polyarthritic and often underweight

C. Ruddlesdin. FRCS. Consultant Orthopaedic Surgeon Barnsley District General Hospital, Gawber Road, Barnsley, South Yorkshire S75 2EP. England.

M. Swann. FRCS. Consultant Orthopaedic Surgeon

B. M. Ansell, CBE, MD, FRCP, Consultant Rheumatologist

Wexham Park Hospital. Slough, Berkshire SL2 4HL, England

G. P. Arden. FRCS, Consultant Orthopaedic Surgeon

1 Dorset Road. Windsor, Berkshire SL4 3BA. England.

Requests for reprints should be sent to Mr M. Swann.

c 1986 British Editorial Society of Bone and Joint Surgery $0301620 \times 86,2015 \$ 2.00$ so put less stress on components and wear is minimal. It has been estimated that component wear should not be a problem for at least 25 to 30 years (Halley and Charnley 1975).

Several technical difficulties are associated with operations on these joints, but need not be contra-indications if a full pre-operative assessment is made, including the possible requirement for custom-made prostheses.

\section{MATERIAL}

Between 1969 and 198175 total hip replacements were performed in 42 children with juvenile chronic arthritis from the Juvenile Rheumatism Unit at the Canadian Red Cross Memorial Hospital, Taplow. The indication for the operation was uncontrollable pain in a severely destroyed stiff joint after treatment with a full medical regime including drugs, splints and physiotherapy. The mean age at operation was 14 years 8 months (Table I). The mean follow-up was 5.4 years (range 1 to 12 years).

Table I. Age in years at the time of operation

\begin{tabular}{lccccccc}
\hline & \multicolumn{3}{c}{ Age (years) } & & & & \\
\cline { 2 - 6 } & $11^{*}$ & $12^{*}$ & $13^{*}$ & 14 & 15 & 16 \\
\hline Number of patients & 3 & 3 & 11 & 8 & 7 & 10 \\
\hline * Only two patients with seropositive disease were under 14 years old at
\end{tabular}
the time of operation

There were 38 girls and 4 boys; 33 of them had bilateral total hip replacement before they were 17 years old. Of the other nine patients who had one hip replaced by this age, five needed a second replacement afterwards, later than the age range included in this report. This indicates the symmetrical nature of the disease in this young 
group of patients. The interval between the onset of arthritis and surgery averaged 7.4 years, whilst the mean interval between symptoms of hip involvement and hip replacement was 5.5 years. Our patients came from several of the subgroups of juvenile chronic arthritis: 15 had systemic onset, 10 were seronegative and polyarticular, 12 seropositive and polyarticular, 3 pauci-articular and 2 psoriatic. There were no patients with ankylosing spondylitis.

Before their hip replacement operations these 42 children had undergone 57 other procedures on joints, 9 at the hip, 40 at the knee and 8 on the upper limbs. Before operation 10 children were confined to a wheelchair and 17 others had had to use walking aids for an average of 2.3 years.

\section{TECHNIQUE OF OPERATION}

Each child was assessed before operation by a team which included a paediatric rheumatologist, an orthopaedic surgeon, an anaesthetist, a nurse, a physiotherapist and an occupational therapist. The operations were performed at either Heatherwood Hospital, Ascot or Wexham Park Hospital, Slough; the patients returned to Taplow 48 hours later for physiotherapy and rehabilitation.

The operations were performed by several surgeons, each using the technique of his choice. Most operations were performed either through a lateral approach with trochanteric osteotomy (47 cases) or by an anterolateral approach ( 24 cases). The various types of prosthesis are listed in Table II; all were implanted with methylmethacrylate cement. Prophylactic antibiotics were used in all

Table II. Type and number of prostheses used in 75 hip replacements

\begin{tabular}{ll}
\hline Type of prosthesis & Number \\
\hline McKee-Arden & 33 \\
Müller & 21 \\
Howse & 16 \\
McKee (metal on metal) & 2 \\
Charnley & 1 \\
Other & 2 \\
\hline
\end{tabular}

Many of these were specially made or were modified to thin-walled cups and shortened stems

cases, but anticoagulant therapy was not employed. Suction drains were usually removed after 48 hours and the patients were allowed to walk with support three days after operation.

These children pose serious anaesthetic problems; in seronegative disease fusion of segments may cause marked stiffness of the cervical spine, while seropositive disease may lead to instability which, particularly at the atlanto-axial joint, presents a hazard. Problems in the cervical spine are often associated with hypoplasia of the mandible and stiffness of the temporomandibular joints. Considerable difficulty may be encountered in intubation and maintenance of the airway under conventional anaesthesia, though fibre-optically guided intubation is helpful.

The majority of our earlier hip operations were performed under ketamine anaesthesia, but the disadvantages of patient movement, extra blood loss and postoperative hallucinations now make this a technique for use as a last resort (Smith 1985). We have had no experience of the methods of regional anaesthesia suggested by Scott, Sarokhan and Dalziel (1984).

\section{RESULTS}

Pain. Pain was scored on a scale from 0 to 10 according to the criteria of Salvati and Wilson (1973); zero denotes

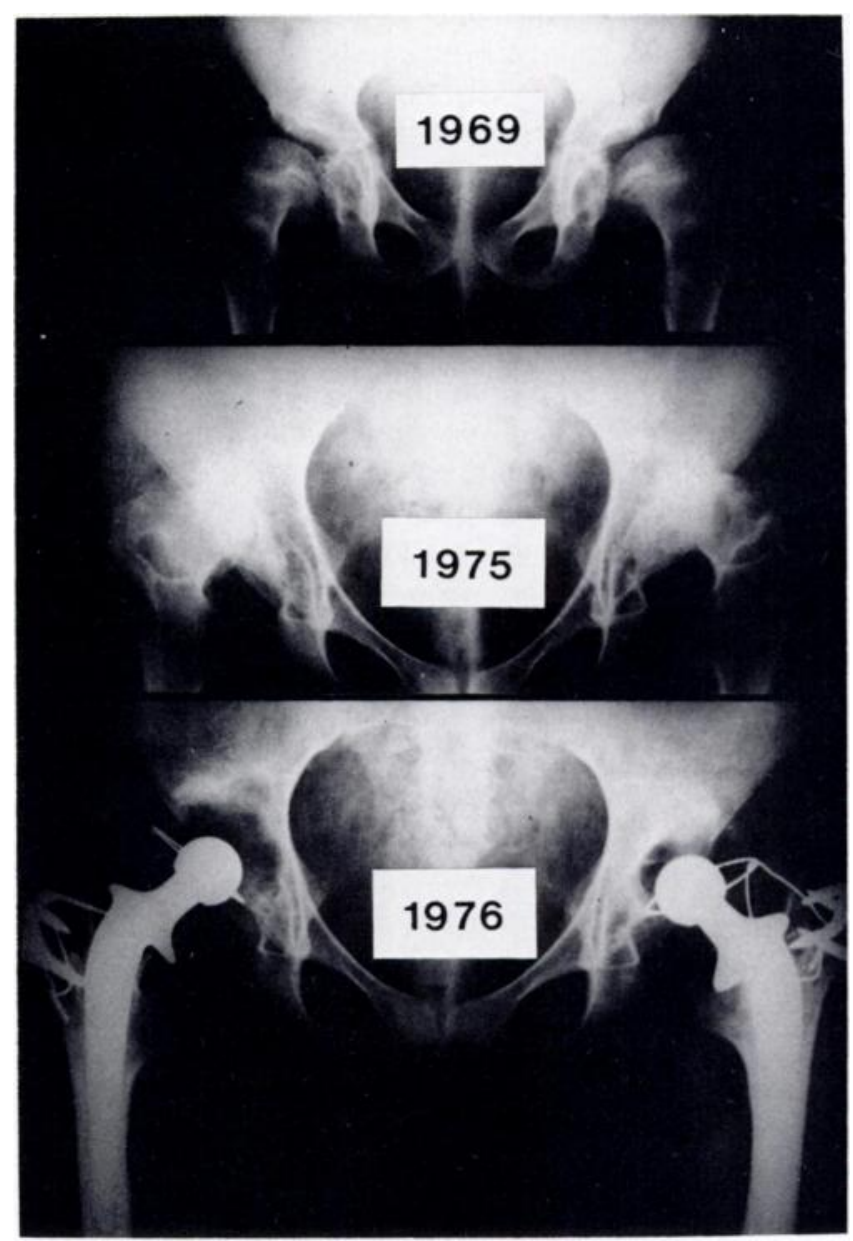

Fig. 1

Radiographs of a girl who developed pauci-articular juvenile arthritis when she was eight months old, and later suffered polyarticular disease and iridocyclitis. In 1969, at the age of 9 years, there is bilateral coxa magna, with anteversion and valgus angulation of the neck of the femur, subluxation of the femoral head and acetabular dysplasia. This has been caused by a combination of disease within the joints and the inability to take weight on them. In 1975, at the age of 15 years, painful arthritis is established and there has been premature closure of the growth plate of the capital epiphysis. In 1976, at the age of 16, bilateral total hip replacement has been completed. Overgrowth of the lesser trochanter has been caused by psoas spasm. 
constant unendurable pain and 10 denotes absence of pain. The dramatic relief produced by operation is demonstrated in Table III. The mean pre-operative score was 1.4 and the postoperative score averaged 9.3 , showing a mean improvement of 7.9 points.

Movement. To obtain a simple figure for purposes of comparison, the aggregate of flexion, abduction and adduction movements was used. The average range of movement before joint replacement was 58 and one year after operation it was 139 . This improvement was maintained in most cases during later follow-up.

Walking. Before operation 17 patients used crutches or frames for support and 10 patients were confined to wheelchairs. After operation only seven patients required walking aids and the three children who remained chairbound all had complete relief of pain.

Growth. The average height of the children before operation was $1.47 \mathrm{~m}$. At the time of review their height had increased by an average of $8 \mathrm{~cm}$ to a mean of $1.55 \mathrm{~m}$. The method of measurement made allowance for any fixed flexion at the hip and at the knee.

Social development. Most of these patients are still being educated but 17 of the older ones now have useful employment in sedentary occupations. They also have a wide range of recreations: four enjoy swimming, five like dancing, one plays badminton (although this is deemed unwise) and one girl persists in stock-car racing despite repeated warnings. Three women have married, and report satisfactory sexual relationships with their husbands. Of the 36 patients aged over 17 years, 32 hold a driving licence. Driving is claimed as the most important single factor in their new-found sense of independence.

Complications. One hip dislocated on a single occasion and was successfully reduced, one haematoma resorbed, and one case of lateral popliteal nerve palsy took a year to recover spontaneously. There was loosening of one femoral component after nine years; this was revised and remains sound after a further two years. Radiographs of one femoral and one acetabular component show some lucencies but both are at present symptomless. There were no cases of infection.

\section{DISCUSSION}

Only one other series has been reported which is comparable in regard to the number and the age of patients, and the disease process. Singsen et al. (1978) report 26 total hip replacements for juvenile chronic arthritis in 14 children aged between 12 and 18 years. Our results with regard to the relief of pain and improvement in range of movement agree with theirs, and our indications for surgery are directly comparable with theirs in that pain was the most prominent factor in all our patients, though stiffness and deformity were also taken into account.

Scott et al. (1984) reported a series of hip and knee arthroplasties for juvenile chronic arthritis but gave no details of age, other than that the youngest was 11 years old. They suggested that functional impairment and
Table III. Levels of pain using the grades of Salvati and Wilson (1973). before and after operation in 75 hips

\begin{tabular}{|c|c|c|c|}
\hline \multirow{2}{*}{\multicolumn{2}{|c|}{ Pain level }} & \multicolumn{2}{|c|}{ Number of hips } \\
\hline & & \multirow{2}{*}{$\begin{array}{l}\text { Before } \\
\text { operation }\end{array}$} & \multirow{2}{*}{$\begin{array}{l}\text { After } \\
\text { operation }\end{array}$} \\
\hline Grade & Symptom & & \\
\hline 0 & Severe pain at rest & 42 & 0 \\
\hline 2 & Constant but bearable with analgesia & 19 & 2 \\
\hline 4 & None at rest. present on activity & 11 & 3 \\
\hline 6 & Pain only on starting activity & 3 & 0 \\
\hline 8 & Occasional slight pain & 0 & 10 \\
\hline 10 & No pain & 0 & 60 \\
\hline
\end{tabular}

deformity rather than pain were the primary indications for operation. Halley and Charnley (1975) state that hip stiffness rather than pain was the most disabling feature before operation in their series of young hip replacements. Perhaps these reports reflect the average age of the patients: the younger adolescent cases reported by Singsen $e t$ al. and ourselves still have active inflammatory disease whilst in the young adults of the other two series the disease had "burnt out" leaving residual contracture and deformity, but no active inflammation. In the series of Halley and Charnley (1975) the average age of 68 hip replacements was 25.9 years but only nine were in patients with Still's disease and 30 were for adult rheumatoid patients. The average age of the subgroup with Still's disease was 24.8 years; eight of the nine were free of pain after operation. Halley and Charnley also confirm the original findings of Charnley and Cupic (1973) that wear of components is not likely to be a problem in these patients.

Bisla, Inglis and Ranawat (1976) report a series of 67 hip replacements in 45 patients under 30 years of age, but only 26 of these patients had juvenile chronic arthritis and only three were aged 15 or under, while six patients were aged from 16 to 20 years. On the same pain scoring system that we used (Salvati and Wilson 1973) they found a similar improvement of 6.5 points. Colville and Raunio (1979) report a series of 59 arthroplasties in 41 patients with a mean age of 30.5 years, but none of their patients were under the age of 18 years at the time of operation.

All these reports agree that operation achieves reduced dependence on walking aids and wheelchairs. Patients who remain chairbound are relieved of pain both at rest and on transfer from bed to chair. We agree with Singsen et al. on growth potential; in normal individuals growth at the normal proximal femoral epiphysis accounts for only $0.8 \%$ of the mean expected height (Reed and Stuart 1959). Over half of our patients have shown significant continued growth after total hip replacement.

All the authors stress the technical difficulties of operation on these children; difficulties which stem from hypoplasia of the pelvis and femur, gross anteversion of 


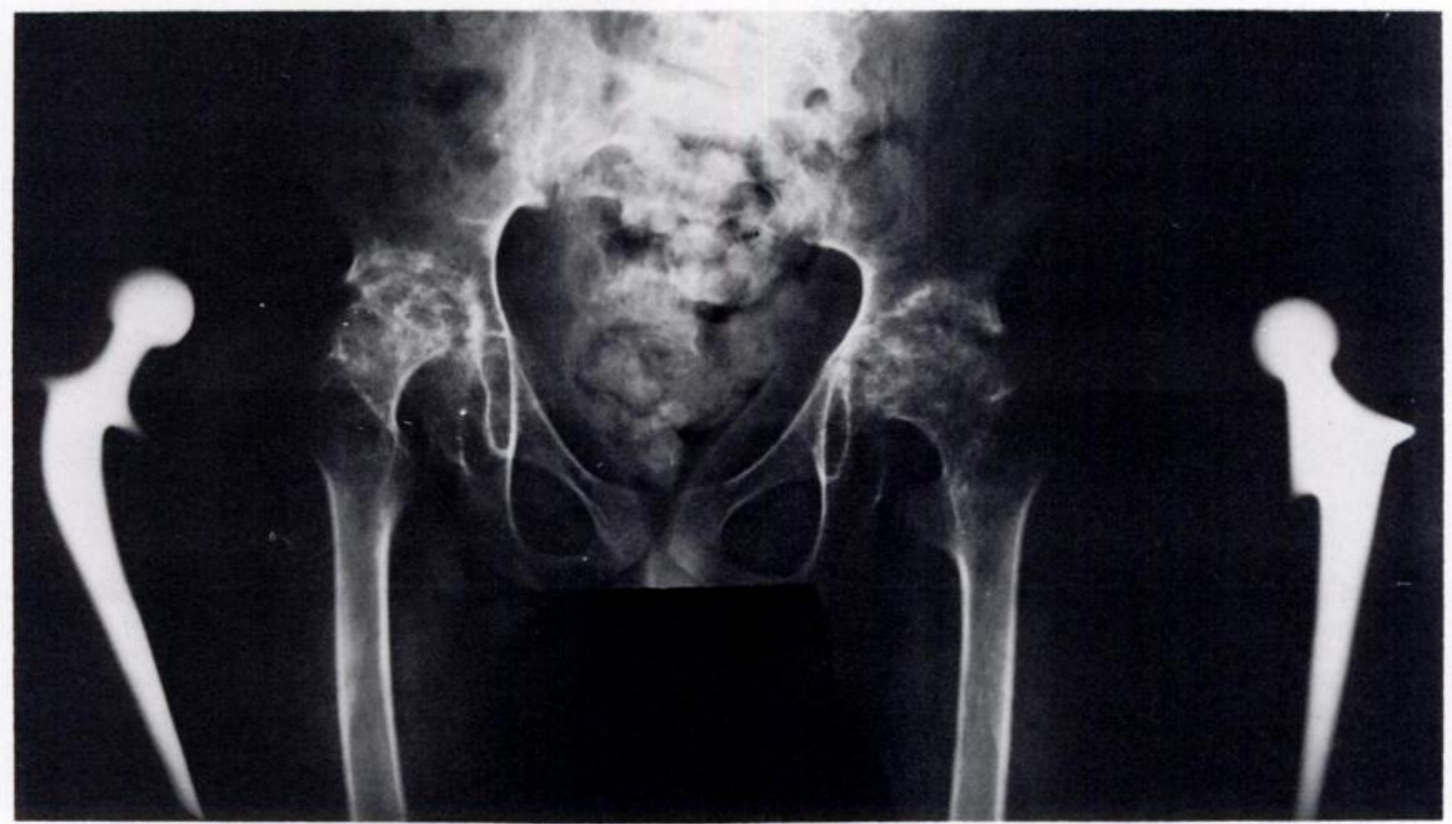

Fig. 2

Radiographs of the hips and the possible prostheses at the same magnification. Similar lateral views should be taken because the upper femoral shaft is sometimes abnormally curved. This boy developed systematic disease leading to polyarthritis when he was aged two, and the hips were replaced when he was 15 years old

the femoral neck. generalised osteoporosis and marked soft-tissue contracture. However, there is no unanimous advice on the management of these difficulties.

Fibrous ankylosis may make dislocation of the hip impossible. and then osteotomy of the neck is needed before the remaining femoral head is removed piecemeal. We have not tried to position the acetabular cup at the true anatomical level and doubt whether this would be possible, even using bone grafts, without extensive release of contracted soft tissues. We stress the importance of having a range of small femoral prostheses readily available before the operation to avoid the need for the intra-operative engineering described by Bisla $e t$ al. (1976). We have found it useful to obtain a radiograph of the pelvis with the chosen prostheses positioned alongside the affected hip and at an equal distance from the radiographic plate (Fig. 2). Lateral as well as anteroposterior radiographs are essential since the upper femoral shaft may have marked anterior bowing in these cases.

There has been considerable discussion of the importance of femoral neck anteversion and its correction (Bisla et al. 1976: Scott et al. 1984) but in our experience it has been difficult to control the eventual alignment of the femoral component: this has assumed an attitude of extreme anteversion (90) in some cases. This is only partly due to the anteversion of the femoral neck, which could be overcome by removal of the neck as well as the femoral head. More important is the crosssectional shape of the femoral canal which may have a

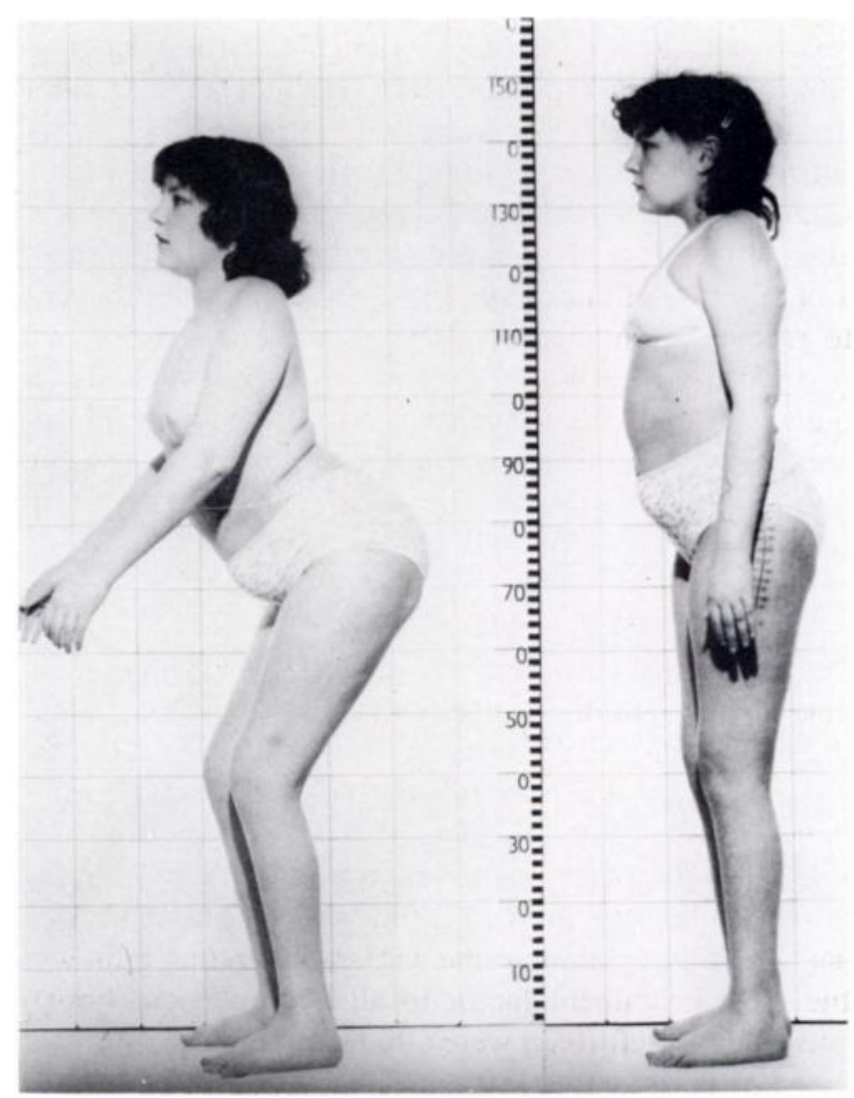

Fig. 3

A patient photographed before and after total hip replacement at the age of 13 years. She had developed the disease at the age of four years but her hips only became significantly involved when she was 12 . 
greater sagittal than coronal diameter. We have not had postoperative problems with severe malrotation of the limb nor with hip instability, provided that the acetabular cup had been fixed without excessive anteversion.

Total replacement of a joint in a growing child is not an operation to be undertaken lightly; it should be reserved for the worst cases, those in which a hip is severely limiting the child's physical capacity and ability to walk (Fig. 3). With careful selection of patients, hip arthroplasty for children with juvenile chronic arthritis has proved to be worthwhile, provided that the technical difficulties are fully appreciated. Many of the earlier reservations regarding total joint replacement for these patients seem to have been unfounded.

\section{REFERENCES}

Ansell BM. Introduction. In: Arden GP. Ansell BM. eds. Surgical management of juvenile chronic polyarthritis. London: Academic Press. New York: Grune \& Stratton. 1978:1 7

Bagó J, Aguirre M, Nardi J, Tallada N. Malignant fibrous histocytoma of bone at the site of a total hip arthroplasty: a case report. $J$ Bone Joint Surg $[\mathrm{Br}]$ 1984;66-B:38-40.

Bisla RS, Inglis AE, Ranawat CS. Joint replacement surgery in patients under thirty. J Bone Joint Surg $[A m]$ 1976:58 A : 1098-104.

Charnley J, Cupic $\boldsymbol{Z}$. The nine and ten year results of the low-friction arthroplasty of the hip. Clin Orthop 1973:95:9-25.

Colville J, Raunio P. Total hip replacement in juvenile rheumatoid arthritis: analysis of 59 hips. Acta Orthop Scand 1979:50: 197-203.
Halley DK, Charnley J. Results of low friction arthroplasty in patients thirty years of age or younger. Clin Orthop 1975:112:180 91 .

Reed RB, Stuart HC. Patterns of growth on height and weight from birth to eighteen years of age. Pediatrics 1959;24:904-21.

Salvati EA, Wilson PD Jr. Lond-term results of femoral head replacement. J Bone Joint Surg $[\mathrm{Am}]$ 1973:55 A:516 24.

Scott RD, Sarokhan AJ, Dalziel R. Total hip and total knee arthroplasty in juvenile rheumatoid arthritis. Clin Orihop 1984;182: 908.

Singsen BH, Isaacson AS, Bernstein BH, et al. Total hip replacement in children with arthritis. Arthritis Rheum 1978:21:401-6.

Smith BL. Anaesthesia and Still's disease. Anaesthesia 1985:40:209 (corresp). 